\title{
Symptomatic intraventricular xanthogranulomas
}

\author{
Samruay Shuangshoti \\ Faculty of Medicine, Chulalongkorn University, Bangkok 10330, Thailand
}

\begin{abstract}
This article reviews symptomatic intraventricular xanthogranulomas, based on a case presentation. Bilateral xanthogranulomas of the choroid plexus were removed surgically from the lateral ventricles of a 12-year-old boy. At 9 years of age, he had evidence of increased intracranial pressure and was hospitalized. Dense enhancing masses were detected in computerized tomogram (CT) brain scan. The lesions were in the region of trigones with extension into the temporal horns and into the right occipital horn. The masses were brightly yellow and greasy. They measured $8.5 \times 5.5 \times 3.5 \mathrm{~cm}$ and $10 \times 6.5 \times 4.5 \mathrm{~cm}$, respectively, and proved to be xanthogranulomas. Review of 35 reported symptomatic intraventricular xanthogranulomas revealed 11 lesions in the lateral ventricles in which six of them were bilateral. Twenty-two lesions were in the third ventricle, and two lesions were in the fourth ventricle. The lesion shows no significant sexual predilection. The patients' average age is 37.6 years for males, 32.4 years for females, and 34.3 years for both sexes. The size of symptomatic lesions ranged from 1 to $3 \mathrm{~cm}$ in diameter but a few were large, up to 8 to $10 \mathrm{~cm}$. The origin of foamy (xanthoma) cells in the xanthogranulomas arising in the choroid plexus is thought to be multicentric including the choroidal epithelium and stromal arachnoidal cells that have undergone xanthomatous changes. Increased intracranial pressure is the significant clinical feature of the intraventricular xanthogranulomas as in other mass lesions within the skull. Surgical extirpation is the treatment of choice if the lesion is accessible and the patient's general condition is suitable.
\end{abstract}

Keywords: Choroid plexus, increased intracranial pressure, xanthogranuloma, xanthoma

Xanthogranulomas occur in various organs of animals including man. In the nervous system, they have been encountered within as well as outside the central nervous system [1, 2]. Both symptomatic and asymptomatic lesions arise throughout the neuraxis including the meninges. In this article, however, only symptomatic intraventricular xanthogranulomas are touched. To the author's knowledge, 35 instances of symptomatic intraventricular xanthogranulomas were reported in the medical literature: 11 lesions occurred in the lateral ventricles [3-13]; 22 lesions were in the third ventricles [9, 14-31]; and two lesions were in the fourth ventricles [32, 33]. Two cases were reported from Thailand; one was in the third ventricle [16], and the other was bilateral intraventricular [8]. The latter is now re-described with particular reference to pathologic features. The literature

Correspondence to: Dr. Samruay Shuangshoti, Emeritus Professor of Pathology, Faculty of Medicine, Chulalongkorn University, Bangkok 10330, Thailand. concerning various aspects of the intraventricular xanthogranulomas is also reviewed.

\section{Case presentation}

At Nakorn Chiang Mai Hospital in 1987, a 12year-old boy was admitted because of visual and auditory hallucinations in which a psychiatric cause had been excluded. At three years and nine months of age, he developed polyuria and was diagnosed to have diabetes insipidus. At nine years of age, he had seizure, nausea, vomiting secondary optic atrophy, hyperreflexia, bilateral plantar dorsiflexion, cranial suture diastasis, and deepening of the sella turcica. These findings were considered to represent evidence of increased intracranial pressure.

The dense enhancing, large, and lobular masses were later detected in computed tomogram (CT) brain scan. They were in the trigones of the lateral ventricles. The lumps extended into the temporal horns of the latter. On the right side, the lesion also extended into the ipsilateral occipital horn. 
The patient underwent exploratory craniotomy through the posterior aspect of the left parietal region. A hard, nodular, and vascular mass was noted in the left lateral ventricle; it was biopsied. Pathologically, it contained abundant large foamy cells in which Oilred-O positive droplets of lipid were detected in their perikaryon. None was positive in glial fibrillary acidic protein in immunostained section of tissue. These foamy cells, hence, were regarded to be nonglial in nature. There were numerous lymphocytes, histiocytes, plasma cells, and multinucleated giant cells of foreign-body type. The sheets and clusters of these cells including the foamy cells were supported by abundant blood vessels especially the small ones. Necrotic foci and clefts of cholesterol crystals were occasionally observed (Fig. 1-3). The lesion, then, was diagnosed pathologically as xanthogranuloma from left lateral ventricle of the brain.

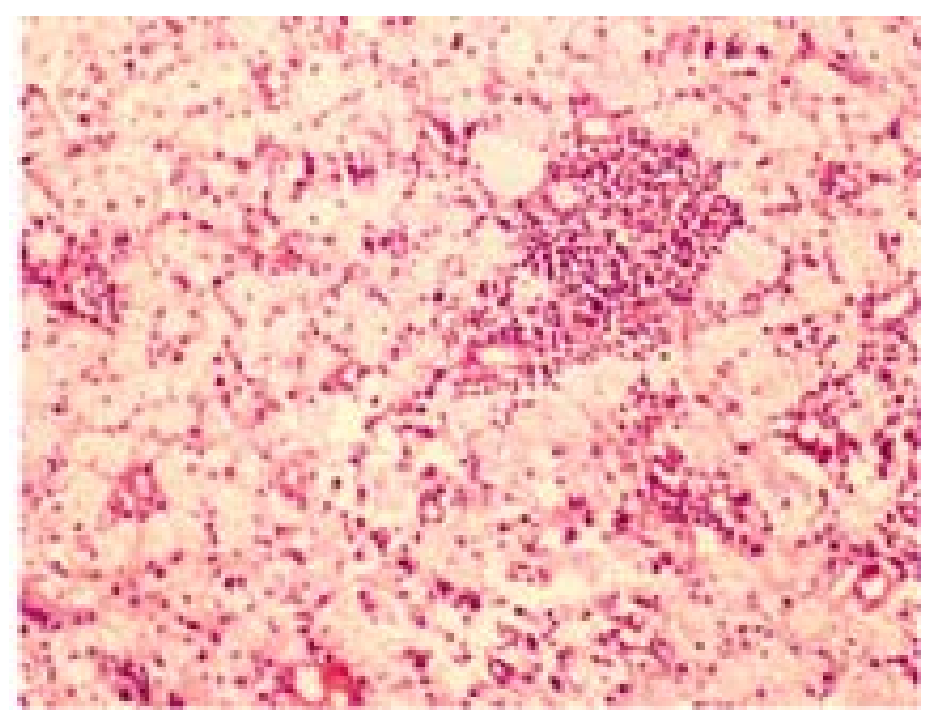

Fig.1 Microscopic feature of the xanthogranuloma as seen in the biopsy. Note sheet of foamy cells, cluster of lymphocytes and histiocytes, and many small blood vessels. Hematoxylin-eosin stain, x 100.

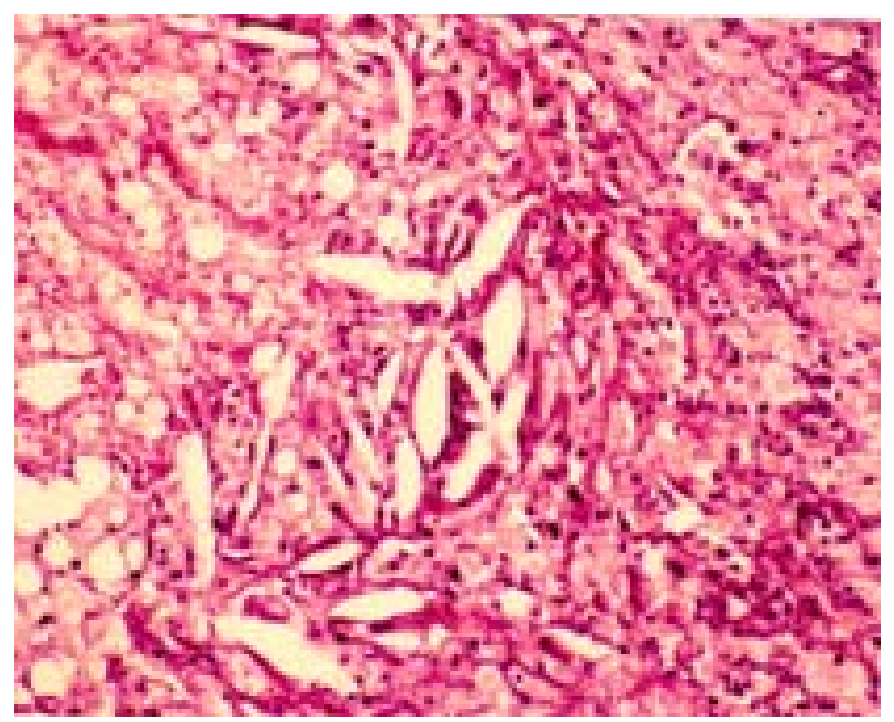

Fig. 2 Microscopic picture of the xanthogranuloma as observed in the biopsy. Many foamy cells, clefts of cholesterol crystals, and a focus of necrosis at the left upper corner are depicted. Hematoxylin-eosin stain, x 100. 


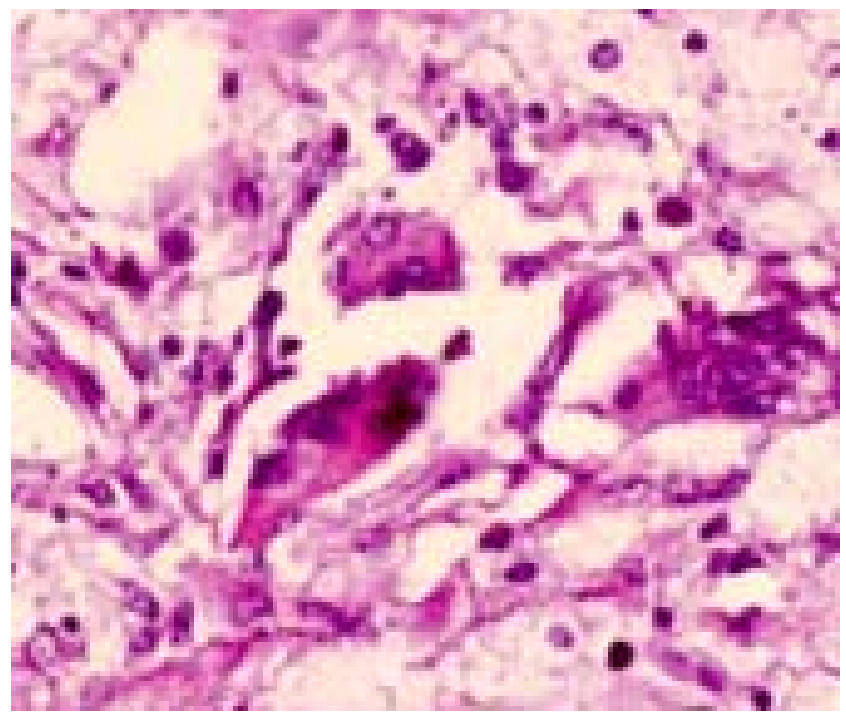

Fig. 3 Few foreign-body type giant cells and foamy cells are demonstrated within the xanthogranuloma. Hematoxylineosin stain, $\mathrm{x} 400$.

After knowing the pathologic diagnosis, the patient underwent total removal of the biventricular tumifactions. Unfortunately, he died immediately although the masses were successfully extirpated. They were yellow, nodular, and firm. Thin capsule covered each of them (Fig. 4). The bisected surface was bright yellow and greasy (Fig. 5). They measured $8.5 \times 5.5 \times 3.5 \mathrm{~cm}$ and $10 \times 6.5 \times 4.5 \mathrm{~cm}$, respectively. Microscopically, they were the same as described in the biopsied specimen. The final pathological diagnosis, then, was bilateral xanthogranulomas from the lateral ventricles of the brain.

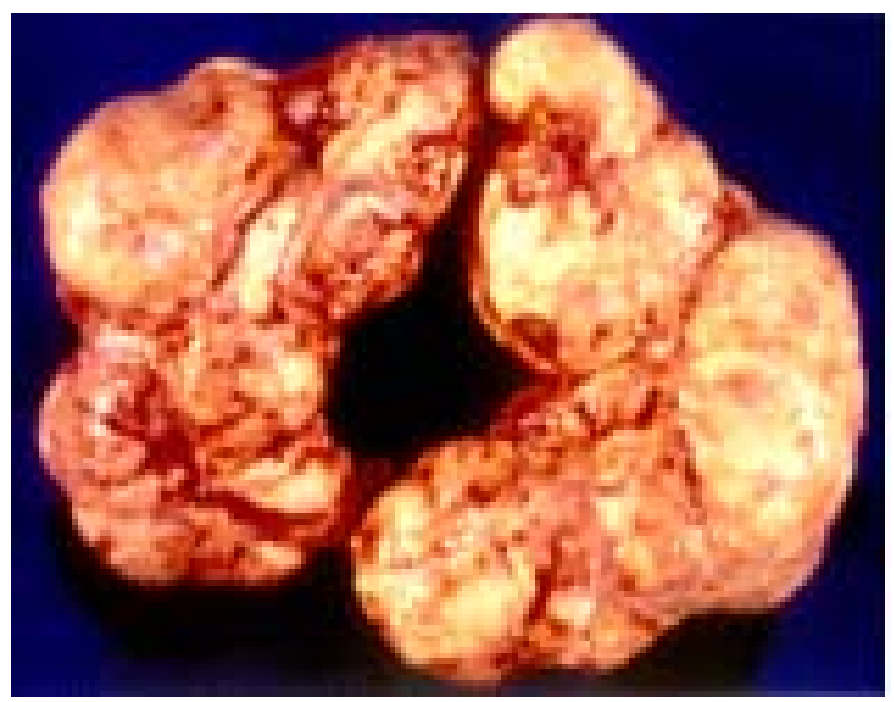

Fig. 4 Gross feature of bilateral xanthogranulomas from the lateral ventricles. Note yellow and nodular external surface covered by thin capsule. 


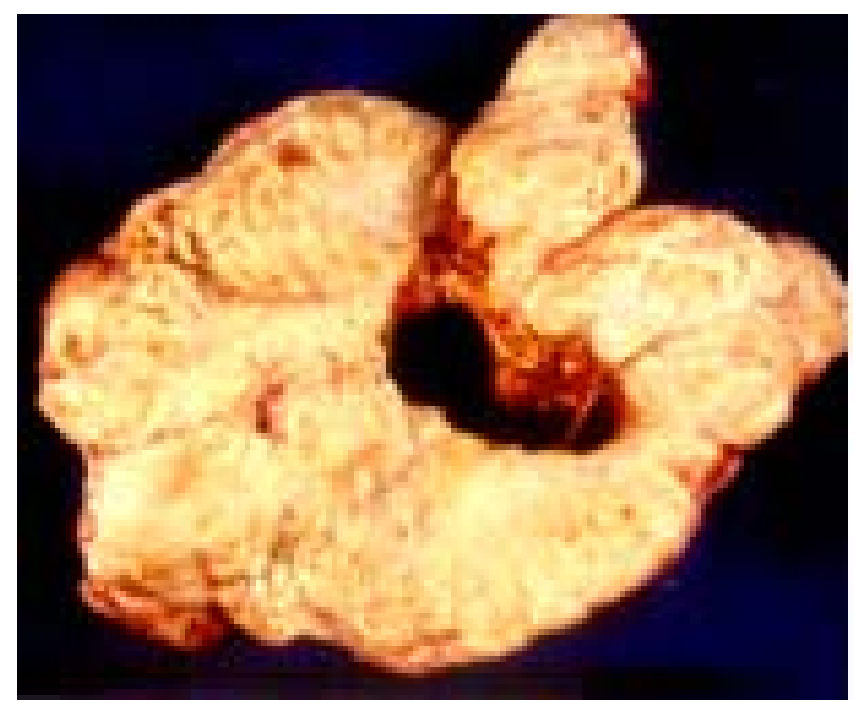

Fig. 5 Bisected xanthogranuloma shows bright yellow and greasy inner surface.

\section{Discussion \\ General consideration}

Definite connection between xanthogranulomatous masses and choroid plexuses was stated in several reported examples [3, 5-7, 9, 12-14, 21, 32]. However, in the current case, no trace of the choroid plexus is noted in the huge lesion. Nevertheless, it is reasonable to assume that the lesions were related to the choroid plexuses of the lateral ventricles in view of their bilaterality and entire confinement within the lateral ventricles, especially in the region of the trigones as depicted in CT scan of the brain. Some lesions were combined neuroepithelial (colloid) cysts and xanthogranulomas [9,16,18,20,22,23,27,28,30,33] . Others were presumably solid xanthogranulomas.

Of 35 symptomatic intraventricular xanthogranulomas encountered in this review, there were 11 lesions in the lateral ventricles, 22 lesions in the third ventricles, and two lesions in the fourth ventricle. It is unexplainable as to why the lesion is more common in the third ventricle than in the lateral ventricle despite the lateral ventricle is more voluminous than the third ventricle and that the size of both lateral ventricular choroid plexuses is larger than the choroid plexus in the third ventricle.

\section{Age and sex}

Table 1 shows distribution of the age and sex of 35 patients having symptomatic intraventricular xanthogranulomas of the brain. The lesion is most common in the third decade (20\%). They appear equally in the fourth and sixth decades (17.0\% each), and in the second and seventh decades (8.6\% each). There were three youngest patients (one male [11] and two females [5, 13]; each aged six years. The oldest patient was 68-year-old woman [6]. The average age is 37.6 years for males, 32.4 years for females and 34.3 years for both genders. There were 18 males and 17 females suggesting no significant difference in sexual distribution in this series of small number of patients.

\section{Size of lesions}

The size of symptomatic intraventricular xanthogranulomas was recorded in a small number of cases. Generally, they ranged between $1 \mathrm{~cm}$ in the fourth ventricle [33] to $3.2 \times 3 \times 2.5 \mathrm{~cm}$ in greatest dimension in the lateral ventricle $[3,5-7,9,10,12,28$, 29, 31-33]. However, there were a few gigantic xanthogranulomas occurring in the lateral ventricles eg 9 x 4 x $3 \mathrm{~cm}$ [4], $8.5 \times 5.5 \times 3.5 \mathrm{~cm}$, and $10 \times 6.5 \times$ $4.5 \mathrm{~cm}$ (current case), $8 \times 3 \times 2.5 \mathrm{~cm}$, and $8.5 \times 4.5 \times$ $1.2 \mathrm{~cm}$ [11]. Nevertheless, lump of more than $1 \mathrm{~cm}$ across may be accidentally found in autopsy. For example, masses of $1.8 \times 1.2 \times 1 \mathrm{~cm}$ and $2.2 \times 1.5 \times$ $1.2 \mathrm{~cm}$ in the lateral ventricles of 59-year-old man caused neither nervous nor mental symptoms [34]. Bilateral masses, $1.7 \times 1 \mathrm{~cm}$ each were found accidentally in the brain of a 51-year-old man who died of chronic hypertensive cardiovascular and renal 
Table 1. Age and sex distribution in 35 patients having intraventricular xanthogranulomas of brain.

\begin{tabular}{lcccr}
\hline $\begin{array}{c}\text { Age decade } \\
\text { (years) }\end{array}$ & $\begin{array}{c}\text { Number } \\
\text { of males }\end{array}$ & $\begin{array}{c}\text { Number } \\
\text { of females }\end{array}$ & $\begin{array}{c}\text { Total } \\
\text { number }\end{array}$ & Percent \\
\hline $0-10$ & 2 & 3 & 5 & 14.3 \\
$11-20$ & 1 & 2 & 3 & 8.6 \\
$21-30$ & 3 & 4 & 7 & 20.0 \\
$31-40$ & 3 & 3 & 6 & 17.0 \\
$41-50$ & 4 & 1 & 5 & 14.3 \\
$51-60$ & 4 & 2 & 6 & 17.0 \\
$61-70$ & 1 & 2 & 3 & 8.6 \\
\hline Total & 18 & 17 & 35 & 100.0 \\
\hline
\end{tabular}

disease [35]. The lesion has been rarely weighed. Nevertheless, the weight of $30 \mathrm{gm}$ on the right side and $18 \mathrm{gm}$ on the left side has been recorded in an example of biventricular xanthogranulomas [11].

\section{Mode of occurrence and origin of foamy (xanthoma) cells}

The mode of occurrence of the xanthogranulomas of the choroid plexus has been variously proposed including cellular degeneration [36], tissue reaction to hemorrhage, disturbance of lipid metabolism [37] and proliferation of certain types of cells [34]. Blumer [34] believed that the lesion arose from the endothelium of perivascular lymph spaces, and named it as cholesteatomatous endothelioma. However, it is generally concurred that lymphatic system does not exist in the neuraxis including the choroid plexus. Wolf et al. [37] and Ayres and Haymaker [36] stated that they could trace transitional forms of arachnoidal (meningocytic) cells into fully formed foamy (xanthoma) cells in the choroidal stroma. Shuangshoti and Netsky [35] regarded the foamy cells in the choroidal xanthogranuloma to be altered epithelial cells of the choroid plexus being secondarily changed from proliferation of the epithelium in which they included as well the endothelium. This phenomenon occurs in both normal and pathologic conditions of the choroid plexus, on the surface of the plexus and in the tubules embedded in the stroma of the plexus. The proliferated epithelial cells ultimately desquamate and float in the intervillous clefts if they arise near the surface, or flow into the choroidal interstitium if the basal lamina (basement membrane) is disrupted. Furthermore, the wall of the tubules may be broken if there is excessive accumulation of the epithelial cells in the tubules, presumably due to increased intraluminal pressure. The detached epithelial cells contain lipids and become foamy which cannot be distinguished from the xanthoma cells [38]. However, Shuangshoti and Netsky [35] did not exclude foamy cells from other sources such as from blood stream and foamy macrophages. Degeneration and disintegration of lipidladen foamy cells release lipid into the choroidal matrix which finally result in formation of the xanthogranuloma consisting of collection of cholesterol crystals, giant cells of foreign body type, proliferation of small blood vessels, foci of hemorrhage, granules of hemosiderin, and cacification. Epithelial origin of the foamy cells was also expressed by others who dealt with xanthogranulomas in the third ventricles [16, 21]. Razavi-Encha et al. [24] studied a third ventricular xanthogranuloma electron microscopically and concluded that the leptomeningeal cells were the origin of the xanthoma cells. In the central region of the lesion, however, they encountered intermingling of undifferentiated round cells and foamy cells. RazaviEncha et al. [24] suggested that xanthoma cells represented a heterogenous entity arising from xanthomatous alterations in various types of cells. The current author agrees with their conclusion.

\section{Symptomatology}

Table 2 shows symptoms and signs observed by various authors concerning the intraventricular xanthogranulomas. The significant ones would be headache, nausea, vomiting, and papilledema because they suggest clinically increased intracranial pressure of the subjects. These clinical finding warn ones to investigate further in order to detect correctly the cause of increased intracranial pressure of the patient. Prolonged papilledema may lead to permanent blindness due to atrophy of the head of the optic nerve. Compression of the brainstem by herniated hippocampal gyrus produces secondary brainstem 
hemorrhage with deteriorated consciousness, hemiparesis, pupillary changes, and eventual fatality of the patient. Compression of brainstem by herniated cerebellar tonsils also causes death of the patient because of failure in function of vital centers in the medulla oblongata. These phenomena of brain herniation often accompany raised intracranial pressure [39-42].

\section{Treatment}

Surgical intervention is the treatment of choice. Of 11 cases of the lateral ventricular xanthogranulomas, six were bilateral $[4,5,8,10,11$, 13]; five were unilateral [3, 6, 7, 9, 12]. Of bilateral xanthogranulomas, two masses were removed simultaneously in three patients $[4,5,11]$. One patient died immediately [8]. Only a biopsy was done in one patient [13]; the lesions appeared to spread along the optic tract and chiasm. The patient experienced progressive bilateral visual loss and finally her vision remained at light perception [13]. In the remaining example, the result of surgical treatment was very good in all aspects except for poor vision bilaterally [11]. In another patient, multiple craniotomies were performed with uneventful recovery. However, the patient's general condition was poor because of associated Hand-Schueller-Christian disease with blindness [4]. In two instances, there was no significant change in size of the dilated ventricular system after extirpation of the biventricular lesions $[5,10]$.

Of five unilateral intraventricular xanthogranulomas, the result of surgical treatment was very good in four cases [3, 6, 9, 12]. For example, the patient could return to school as normal and happy youngster [3], free from headache in one and half years [6], well two years after removal of the lesion [9], and full recovery and returned to full-time worker two months after surgical intervention [12]. The result of treatment was less satisfactory in one patient [7] in which he developed homonemous hemianopia after removal of a xanthogranuloma from the choroid plexus of the right lateral ventricle. Nevertheless, parageusia and parosmia disappeared post-operatively [7].

Of 22 third ventricular xanthogranulomas, surgical removal was done in 13 cases with satisfactory result $[9,15,16,18-20,25,28,29,31]$. The less favorable results were obtained in two patients [17, 23]. For instance, the patient was unable to return to work in one [17], and residual dementia in the other [23]. Death occurred in three individuals; within three weeks after hospitalization in one case [21], one week after surgical removal because of meningitis [30], and 22 days after surgical extirpation due to pulmonary embolism [24]. The result of surgical treatment was not stated in 2 instances [26, 27]. Two patients died without specific treatment [14, 22].

Table 2. Significant symptoms and signs in 35 intraventricular xanthogranulomas of brain.

\begin{tabular}{ll}
\hline Symptoms and signs & References \\
\hline Headache & $9,14,17,19,25,30$ \\
Nausea and vomiting & 8,33 \\
Headache, nausea and vomiting & $6,7,9,11,12,15,21,22,25,26,27,28$ \\
Papilledema & $10,15,16,17,23,24,27,30$ \\
Atrophy of optic nerve & 8,11 \\
Double vision & 32 \\
Nystagmus & 3,13 \\
Hemiparesis & $9,11,14$ \\
Ataxia & $15,19,20,23,33$ \\
Seizure & $5,8,14,16,30$ \\
Facial nerve palsy & 32 \\
Hypesthesia over distribution of $2^{\text {nd }}$ branch & 32 \\
$\quad$ of left trigeminal nerve & 31 \\
Loss of sphinctorian control & 7 \\
Parageusia (change of taste) and parosmia & 29 \\
$\quad$ (change of smell) & 5 \\
Deteriorated consciousness & 9 \\
Psychomotor retardation & \\
Changes of personality, confusion and aphasia & \\
\hline
\end{tabular}


Two fourth ventricular xanthogranulomas also showed satisfactory result of surgical treatment. The patient has been well after one year of follow-up study [33]. The other patient lived three years after removal of the lesion [32].

\section{Acknowledgements}

The author highly appreciates the kind permission of Springer Science Business Media for allowing him to re-use materials, which were previously published in "Neuroradiology". This material is indicated in reference 8 of the current article.

The author has no conflict of interest to report.

\section{References}

1. Thomas PK, Walker JG. Xanthomatous neuropathy in primary biliary cirrhosis. Brain. 1965; 88:1079-88.

2. Chermsirivathana S, Nasongara K. Xanthoma tuberosum associated with biliary cirrhosis of the liver. J Med Assoc Thai. 1966; 49:634-44.

3. Rosner S. Xanthoma of the choroid plexus in a child. J Nervous Ment Dis. 1957; 125:339-41

4. Morello A, Campesi G, Bettinazzi N, Albeggiani A. Neoplastiform xanthomatous granulomas of choroid plexus in a child affects by Hand-Schueller-Christian Disease. J Neurosurg.1967; 26:536-41.

5. Terao H, Kobayaski S, Teraoka A, Okeda R. Xanthogranulomas of the choroid plexus in a neuroepileptic child. Case report. J Neurosurg.1978; 48: 649-53.

6. Pear BL. Xanthogranuloma of the choroid plexus. Am J Radol (AJR). 1984; 143:401-2.

7. Rutherfoord GS, Mathew B. Xanthogranuloma of the choroid plexus of lateral ventricle, presenting with parosmia and parageusia. Br J Neurosurg. 1987; 1: 285-8.

8. Handagoon P, Pitakdamrongwong N, Shuangshoti S. Xanthogranulomas of choroid plexus. Neuroradiology. 1987; 29:172-3.

9. Marks PV, Frost NA, Shaw G, Hope A. Symptomatic intraventricular xanthogranulomata. Report of 2 cases. Clin Neurol Neurosurg. 1991; 93-4:283-7.

10. Brueck W, Sander U, Blanckenberg P, Friede RL. Symptomatic xanthogranuloma of choroid plexus with unilateral hydrocephalus: Case report. J Neurosurg. 1991; 75:324-7.

11. Gaskill SJJ, Saldiar V, Rutman J, Marlin AE. Giant bilateral xanthogranulomas in a child: case report. Neurosurg. 1992; 31:114-7.

12. Hicks MJ, Albrecht S, Trask T, Byrne ME, Narayan
RK, Goodman JC. Symptomatic choroid plexus xanthogranuloma of the lateral ventricle. Clin Neuropathol. 1993; 12:92-6.

13. Mendez-Martinez OE, Luzardo-Small GD, CardozoDuron JJ. Symptomatic bilateral xanthogranulomas of choroid plexus in a child. Br J Neurosurg. 2000; 14:62-4.

14. Stern F, Levy F.Ueber eine cholesterinhaltige Geschwulst am plexus chorioideus ventriculi III. Virchow’s Arch Pathol Anat. 1917; 223:272-80.

15. Jaer O, Loken AC, Nesbakken R. Hydrocephalus due to xanthogranuloma: case report. J Neurosurg. 1979; 51:565-8.

16. Shuangshoti S, Phonprasert C, Suwanwela N, Netsky MG. Combined neuroepithelial (colloid) cyst and xanthogranuloma (xanthoma) in the third ventricle. Neurology. 1975; 25:547-52.

17. Rush JL, Kusske JA, Porter RW, Pribran HW. Xanthogranuloma of the third ventricle: case report. J Neurosurg. 1979; 4:329-33.

18. Szper I, Oi S, Leestma J, Kim KS, Wetzel NE. Xanthogranuloma of the third ventricle producing hydrocephalus. Neurosurgery. 1979; 51:565-8.

19. Godersky J, Rockswold G, Larson DA. Xanthogranuloma of the third ventricle producing hydrocephalus. Neurosurgery. 1980; 7:68-70.

20. Antunes L, Kvam D, Ganti SR, Louis KM, Goodman J. Mixed colloid cysts-xanthogranulomas of the third ventricle. Surg Neurol. 1981; 16:256-61.

21. Gherardi R, Ngugen JP, Gaston A, Poirier J. Symptomatic xanthogranuloma of the third ventricle: a clinicopathological report. Eur Neurol. 1984; 23:156-62.

22. Hadfield MG, Ghatak NR, Wanger GP. Xanthogranulomatous colloid cyst of the third ventricle. Acta Neuropathol. 1985; 66:343-6.

23. Matsushimo T, Fukui M, Kitamura K, Soejima T, Ohta M, Okano H. Mixed colloid cyst-xanthogranuloma of the third ventricle: a light and electron microscopic study. Surg Neurol. 1985; 24:457-62.

24. Razavi-Encha F, Gray F, Gaston A, Gherardi R, Caron JP, Poirier J. Symptomatic xantrogranuloma of the choroid plexus of the third ventricle: a new case with ultrastructural study. Surg Neurol. 1987; 27:569-74.

25. Montaldi S, Deruaz J, Cai Z, de Tribolet N. Symptomatic xanthogranuloma of the third ventricle: report of two cases and review of the literature. Surg Neurol. 1989; 32:200-5.

26. Wiot JG, Lukin RR, Tomsick TA. Xanthogranuloma of the third ventricle. Am J Neuroradiol. 1989; 10(Suppl 5): S5.

27. Hiran S, Jain S, Budhiraja A, Bhalla M. Colloid cyst- 
xanthogranuloma of third ventricle: a case report. Neurol India. 1993; 41:117.

28. Tatter SB, Ogilvy CS, Golden JA, Ojemann RG, Louis DN. Third ventricular xanthogranuloma clinically and radiologically mimicking colloid cysts: report of two cases. J Neurosurg. 1994; 81:605-9.

29. Tomita H, Tamaki N, Korosue K, Kokunai T. Xanthogranuloma with massive hematoma in the third ventricle: case report. Neurosurgery. 1996; 39:591-4.

30. Knudesia S, Das S, Shankar SK, Santosh V, Reddy AK. Colloid cyst xanthogranuloma of the third ventricle: a case report. Indian J Pathol Microbiol. 1996; 39:221-3.

31. Miranda P, Lobata RD, Ricoy JR, Lagaresy A, Ramos A. Xanthogranuloma of the choroid plexus of the third ventricle: case report and literature review. Neurocirugia. 2005; 16:517-22.

32. Wang PY, Hung TP, Huang KM, Lin SW, Yao YT. Xanthogranuloma of the fourth ventricle: a case report. J Formosan Med Assoc. 1985; 84:1386-90.

33. Tada M, Koiwa M, Chono Y, Nemoto M, Kashiwaba T, Abe H, Miyasaka K. Neuroepithelial (colloid) cyst of the cerebellar vermis containing a xanthogranuloma. Am J Neuroradiol. 1993; 14:951-3.

34. Blumer G. Bilateral cholesteatomatous endotheliomata of the choroid plexus. Johns Hophins Hosp Rep.1900; 9:270-90.
35. Shuangshoti S, Netsky MG. Xanthogranuloma (xanthoma) of choroid plexus: the origin of foamy (xanthoma) cells. Am J Pathol. 1966; 48:503-33.

36. Ayres WW, Haymaker W. Xanthoma and cholesterol granuloma of the choroid phexus: report of a pathological aspects in 29 cases. J Neuropathol Exp Neurol. 1960; 19:280-95.

37. WolfA, Cowen D, Graham S. Xanthomas of the choroid plexus in man. J Neuropathol Exp Neurol. 1950; 9: 286-97.

38. Shuangshoti S, Netsky MG. Human chosroid plexus: morphologic and histochemical alteration with age. Am J Anat. 1970; 128:73-96.

39. Shuangshoti S, Tangchai P. Neuropathology. Bangkok:Thai Watanapanich Press, 1976; p. 54-123 (also see p. 54-61).

40. Shuangshoti S. Increased intracranial pressure and its effects. Bulletin Lampang Hosp. 1983; 4:39-57.

41. Ironside JW, Pickard JD. Increased intracranial pressure, oedema and hydrocephalus. In: Graham D, Lantos P, editors. Greenfield's Neuropathology. Vol. I, $7^{\text {th }}$ ed. London:Arnold, 2002; p. 193-225.

42. Vinters HV, Kleinschmidt-Dedmasters BK. General pathology of the central nervous system. In: Love s, Louis DN, Ellison DW, editors. Greenfield's Neuropathology. Vol. I, $8^{\text {th }}$ ed. London:Hodder Arnold, 2008; p. 1-62. 